\title{
Continuous Recovery of Gold(III) via Foam Separation with Nonionic Surfactant
}

\author{
T. Kinoshita ${ }^{\text {a,1 }}$, S. Akita ${ }^{\text {a }}$, S. Ozawa ${ }^{\text {b }}$, S. Nii ${ }^{\text {b }}$, F. Kawaizumi ${ }^{\text {b }}$, \\ K. Takahashi ${ }^{\text {b }}$ \\ ${ }^{a}$ Nagoya Municipal Industrial Research Institute, 3-4-41 Rokuban, Atsuta-ku, Nagoya 456- \\ 0058, Japan \\ address $^{1}$ Fax: +81-52-654-6788. \\ e-mail: kinoshita.takehiko@nmiri.city.nagoya.jp \\ ${ }^{b}$ Department of Chemical Engineering, Nagoya University, Chikusa-ku, \\ Nagoya 464-8603, Japan
}

\begin{abstract}
A continuous recovery of $\mathrm{Au}$ (III) via foam separation from its hydrochloric acid solutions was studied using a nonionic surfactant: polyoxyethylene nonyl phenyl ether having 20 ethylene oxide units (PONPE20). The surfactant showed a strong affinity to $\mathrm{Au}(\mathrm{III})$ in $\mathrm{HCl}$ media, and successfully played a dual role for foamproduction and metal-collection in the system. Experimental parameters examined were the feed flow rate, the foam height and the depth of bulk liquid phase. Under a standard condition, the percent recovery and the enrichment ratio of $\mathrm{Au}$ (III) were $54 \%$ and 4.5, respectively. Using the adsorption isotherm of $\mathrm{Au}$ (III) obtained in a batch operation, these two values could be estimated against the feed flow rate which are in good agreement with the experimental ones. It was also found that about $90 \%$ of $\mathrm{Au}$ (III) recovered in the foamate phase was transferred onto the foam surface and the rest was conveyed to the interstitial water between the foam. Highly selective recovery of $\mathrm{Au}$ (III) was achieved from multi-metals solution.
\end{abstract}

Key Words: foam separation, nonionic surfactant, gold(III), continuous operation, surface excess, Freundlich's adsorption isotherm

\section{Introduction}

Foam fractionation plays an important role in diverse fields both for recovering valuable solutes and for rejecting impurities and pollutants in dilute solutions. The advantage of this separation technique is its low cost in energy and operation as well as small installation space. To date various separations have been carried out; hazardous metal ions [1,2], proteins [3,4], mineral ore [1,2,5] and surfactants [6]. In foam fractionation processes, the main roles are played by a foam producing agent, i.e. surfactant and a collecting agent. The former enables stable formation of foam by bubbling aqueous solutions, while the latter collects the target solutes adsorbed on the surface of foam. During a rise of foam through a drainage section of the column, the interstitial water between foam is drained out by gravity, and solutes are concentrated in the foamate phase along with surfactant. There are a number of reports concerning the combination of such collecting agents and target solutes under various conditions [7-10].

A series of polyoxyethylene nonyl phenyl ethers (PONPEs) have a strong interaction with $\mathrm{Au}(\mathrm{III})$ [11,12]. This reagent would be an excellent collector and also performs as a surfactant. Using a multifunctional reagent would simplify the fractionation process. In batch 
operation, the percent recovery of $\mathrm{Au}$ (III) increased with an increase in the surfactant concentration and the air flow rate, while the enrichment ratio improved by decreasing air flow rate and increasing the length of drainage section of the column. Based on the difference in affinity of the surfactant to several metals, selective foam separation of $\mathrm{Au}(\mathrm{III})$ in a multi-metals solutions could be attained. Moreover, the adsorption of $\mathrm{Au}(\mathrm{III})$ on the foam surface was well predicted by Freundlich's adsorption isotherm $\left(\Gamma \times 10^{7}=10.3[\mathrm{M}]_{\mathrm{ret}}{ }^{0.39}\right)$ under the experimental conditions studied.

In this study, a continuous mode operation was carried out to separate $\mathrm{Au}$ (III) from hydrochloric acid solutions using PONPE. Several experimental parameters such as the feed low rate, the foam height and the depth of bulk liquid phase were varied to examine their effects on the recovery and enrichment of $\mathrm{Au}(\mathrm{III})$. Furthermore, using the adsorption isotherm obtained in the batch mode [12], the process efficiency in continuous operation has been estimated and compared with experimental results.

\section{Materials}

Nonionic surfactant, polyoxyethylene nonyl phenyl ether (PONPE20), with average ethylene oxide units of $20\left(\mathrm{HO}\left(\mathrm{CH}_{2} \mathrm{CH}_{2} \mathrm{O}\right)_{20} \mathrm{C}_{6} \mathrm{H}_{4} \mathrm{C}_{9} \mathrm{H}_{19}\right)$ was obtained from Tokyo Kasei Kogyo Co., Ltd. and used without further purification. Aqueous feed solutions were prepared by dissolving prescribed amounts of metal chlorides and the surfactant in hydrochloric acid solutions. All the chemicals used were of reagent grades.

\section{Procedure for Continuous Foam Separation}

A schematic diagram of continuous foam separation apparatus is shown in Figure 1. The bubble column is composed of a cylindrical glass tube $(500 \mathrm{~mm}$ in height and $30 \mathrm{~mm}$ in inner diameter) with a sintered glass filter (G3) mounted at the bottom of the column as a gas distributor. Air was introduced at $40 \mathrm{~cm}^{3} / \min$ through the distributor. A feed solution was brought into the column through an inlet port and an effluent was discharged from the bottom of the column. A pump was used to drain the effluent to keep the liquid depth of $100 \mathrm{~mm}$ from the glass filter, which corresponds to the volume of $71 \mathrm{~cm}^{3}$, unless otherwise stated. The length of the drainage section of the column was $400 \mathrm{~mm}$, except when measurements were conducted on its effect. Foam was collected through a froth collection device equipped at the top of the column.

Initial concentrations of $\mathrm{Au}(\mathrm{III})$, the surfactant and hydrochloric acid in feed solutions were set at $20 \mathrm{ppm}, 0.05 \mathrm{wt} \%$ and $2.0 \mathrm{M}$, respectively. Aliquots of the foamate and effluent solutions were withdrawn at intervals of 10 minutes and analyzed for metal concentrations by inductively coupled plasma spectroscopy (ICP) after appropriate dilution. All the experiments were carried out at $298^{\circ} \mathrm{K}$. 


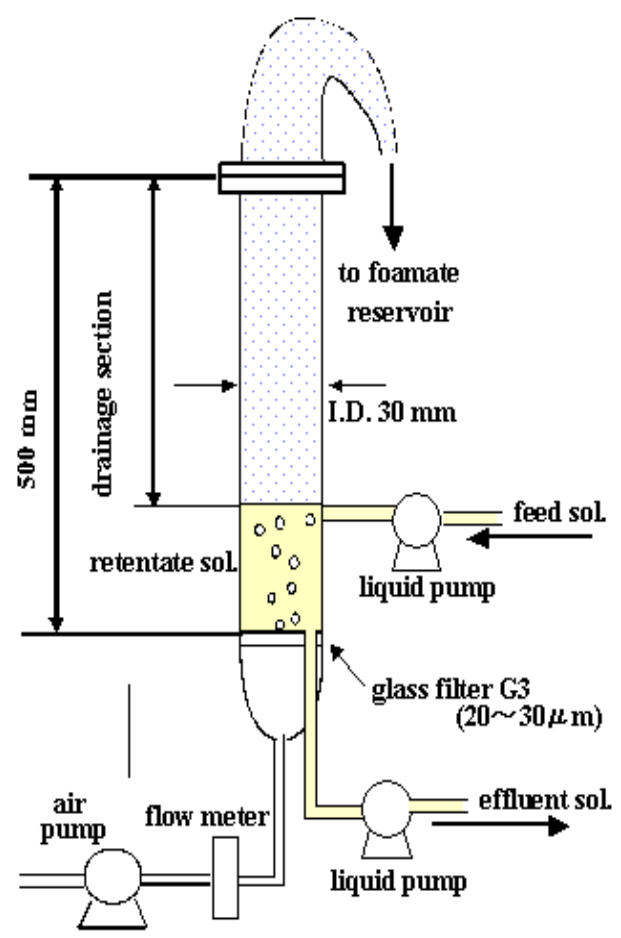

Figure 1. Schematic diagram of foam separation apparatus.

\section{Results and discussion}

\section{Continuous foam separation of Au(III) from hydrochloric acid media}

The recovery percent $(\mathrm{R})$ and the enrichment ratio (E) are defined by the following equations, and used for evaluating the separation efficiency, where $\mathrm{F}$ and $\mathrm{L}$ are the volumetric flow rates of the feed and foamate solutions, respectively. $M$ represents the metal and the subscripts, fm and ini, refer to the foamate and feed phases, respectively.

$$
\begin{aligned}
& \mathrm{R}_{\mathrm{fm}}=100(\mathrm{~L} / \mathrm{F}) \\
& \mathrm{R}_{\mathrm{M}}=100\left(\mathrm{~L}[\mathrm{M}]_{\mathrm{fm}} / \mathrm{F}[\mathrm{M}]_{\mathrm{ini}}\right) \\
& \mathrm{E}=[\mathrm{M}]_{\mathrm{fm}} /[\mathrm{M}]_{\mathrm{ini}}=\mathrm{R}_{\mathrm{M}} / \mathrm{R}_{\mathrm{fm}}
\end{aligned}
$$

A time course of the recovery percent and the enrichment ratio of $\mathrm{Au}(\mathrm{III})$ is shown in Figure 2. The feed concentrations of the metal, surfactant and hydrochloric acid were $20 \mathrm{ppm}$, $0.05 \mathrm{wt} \%$ and $2.0 \mathrm{M}$ respectively. Within retentate solution in the column, the feed liquid and air bubble contact counter-currently. The feed solution and air were supplied at $2.5 \mathrm{~cm}^{3} / \mathrm{min}$ and 40 $\mathrm{cm}^{3} / \mathrm{min}$ respectively. During the run, the discharging rate of the effluent from the column was adjusted to keep a constant height of the retentate solution. After starting to supply air, the foam was produced and the froth grew to fill the column. At the outlet of the column, the foam 
ruptured spontaneously and the liquid was recovered. Due to the high affinity of $\mathrm{Au}$ (III) to the surfactant [11-15], the metal was accumulated in the foamate phase; this could be ascertained by color change to yellow due to $\mathrm{Au}(\mathrm{III})$ enrichment in the phase.

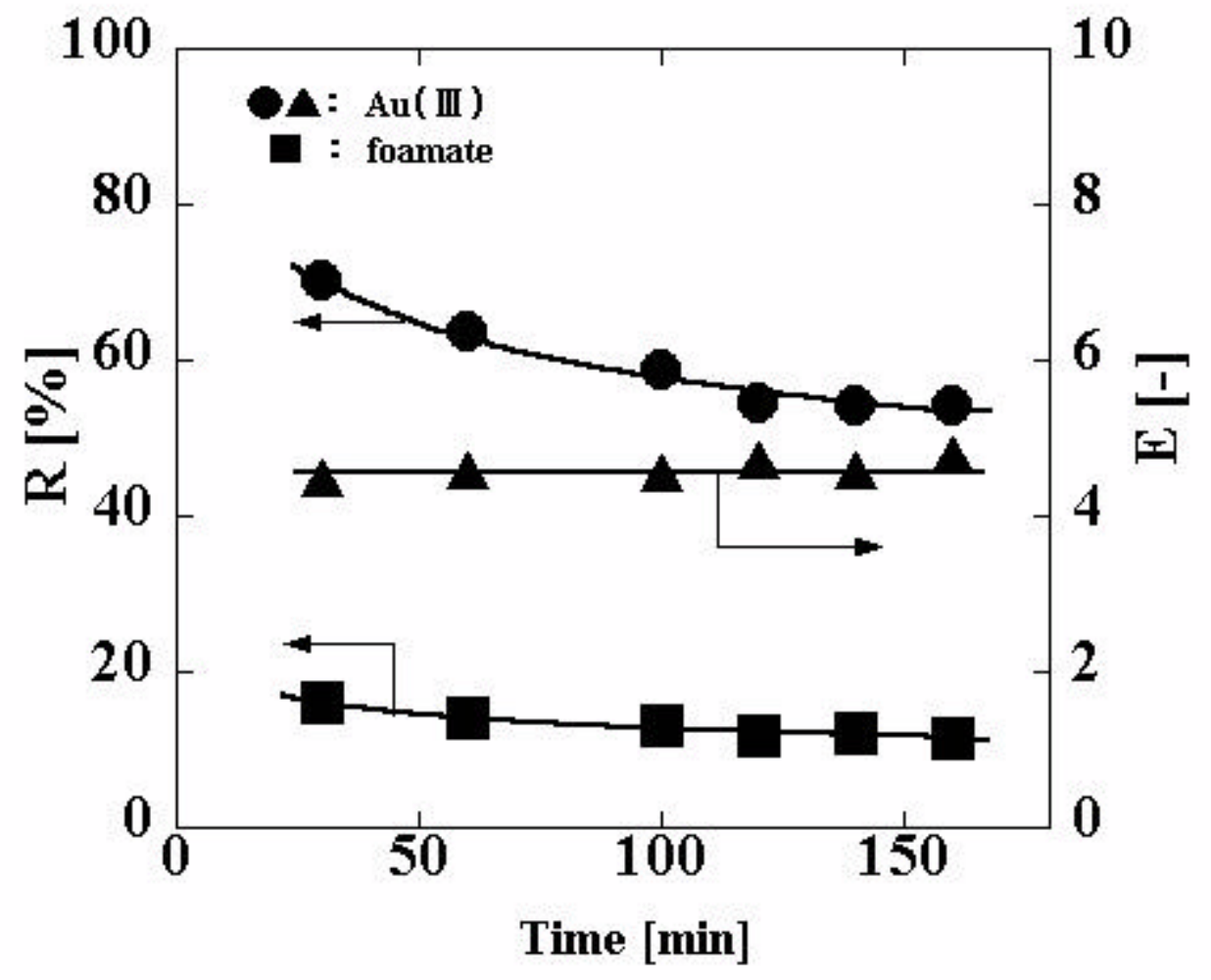

\section{Figure 2. Time course of continuous foam separation of Au(III) using 0.05 wt \% PONPE 20 in $2.0 \mathrm{M} \mathrm{HCl}$.}

The percent recovery of $\mathrm{Au}(\mathrm{III})$ decreases gradually from $73 \%$ with time. Since the foamate recovery shows a similar decreasing trend, their ratio, i.e. the enrichment ratio, gives a nearly constant value of 4.5. Stable operation is attained after $120 \mathrm{~min}$, where the recovery of $\mathrm{Au}$ (III) converges to ca. $55 \%$, which is lower than that $(86 \%)$ obtained in the batch mode under the same experimental condition [12]. In foam separation, solutes are recovered as the components in foamate phase by being transferred either on the foam surface or in the interstitial water between foams. In continuous mode, the foamate recovery $(13 \%)$ is much smaller than the batch mode $(22 \%)$. Therefore, the foamate recovery has a large effect on the metal recovery under a similar enrichment ratio. This is the main reason for the difference of metal recovery in batch modes.

Figure 3 shows the effect of the feed flow rate on the percent recovery and the enrichment ratio of $\mathrm{Au}$ (III) under steady state condition. As the flow rate increases from 1.5 to $4.5 \mathrm{~cm}^{3} / \mathrm{min}$, the foamate recovery declines from 13 to $3.8 \%$. It is thought that increasing the feed flow leads to decrease the rising velocity of bubbles. The foamate generation rate will be decreased and this causes a decrease in the foamate recovery. The significant decrease of metal recovery from 74 to $28 \%$ with increasing feed flow rate is due to shortening of the residence time of the retentate solution in the column. On the other hand, the enrichment ratio of $\mathrm{Au}$ (III) 
improves by increasing the flow rate, and reaches as high as 7.3 at $4.5 \mathrm{~cm}^{3} / \mathrm{min}$. This can be ascribed to the facilitated drainage of interstitial water by reducing the upward flow rate of foam. It should be noted, that there can be a trade-off relationship between the recovery of $\mathrm{Au}$ (III) and the enrichment ratio at a higher flow rate.

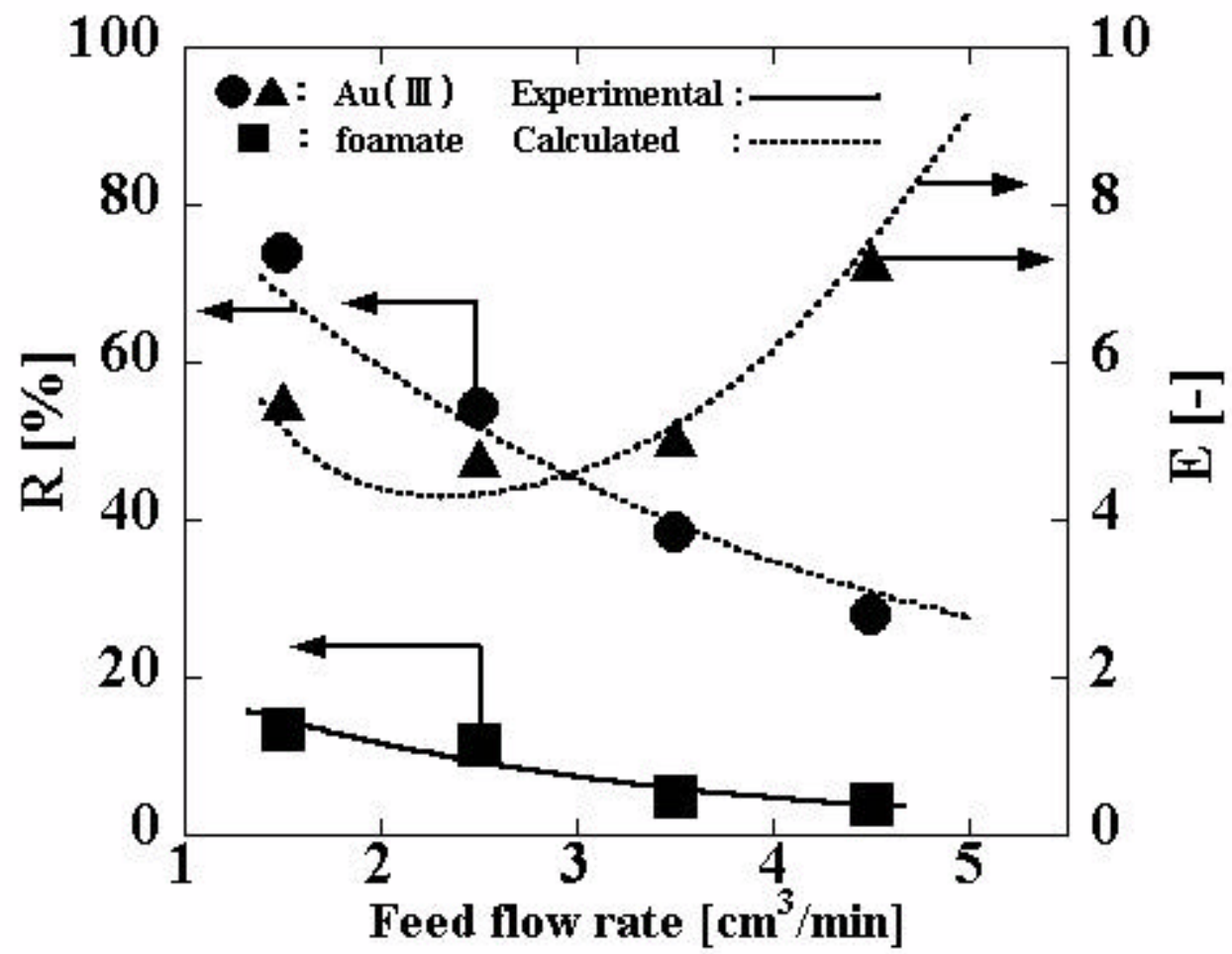

Figure 3. Effect of feed flow rate on percent recovery and enrichment ratio.

In Table 1 are summarized the effects of both height of the retentate solution and length of the drainage section on the separation efficiency. The latter height was altered by inserting extending tubes on the column top. The feed flow rate was set at $2.5 \mathrm{~cm}^{3} / \mathrm{min}$. At a fixed height of solution $(10 \mathrm{~cm})$, extension of the drainage section leads to a significant decrease in the foamate recovery due to facilitated drainage. As for the metal recovery, a constant value of ca. 55 $\%$ was obtained from 40 to $70 \mathrm{~cm}$ of drainage section. The enrichment ratio of $\mathrm{Au}(\mathrm{III})$ improves and reaches as high as 8.9 at the length of $70 \mathrm{~cm}$. Subsequently, the height of the retentate solution was changed for the constant drainage length $(40 \mathrm{~cm})$. By increasing the solution volume, the percent recovery of $\mathrm{Au}(\mathrm{III})$ increases up to $64 \%$. While the foamate recovery decreases from 12 to $18 \%$. These trends cause slight deterioration of the metal enrichment from 4.6 to 3.5. In the following experiments, the length of drainage section and the height of solution were fixed at $10 \mathrm{~cm}$ and $40 \mathrm{~cm}$, respectively. 
Table 1. Effect of length of drainage section and depth of retentate solution.

\begin{tabular}{ccccccc}
\hline Depth of retentate solution $(\mathrm{cm})$ & 10 & 10 & 10 & 10 & 20 & 30 \\
Length of drainage section $(\mathrm{cm})$ & 40 & 50 & 60 & 70 & 40 & 40 \\
\hline ReM $(\%)$ & 54 & 54 & 54 & 56 & 60 & 64 \\
$\operatorname{Refm}(\%)$ & 12 & 8 & 7 & 6 & 14 & 18 \\
En $(-)$ & 4.6 & 6.6 & 8.0 & 8.9 & 4.2 & 3.5 \\
\hline
\end{tabular}

Experiments on the continuous recovery of $\mathrm{Au}(\mathrm{III})$ from a multi-metals solution of $\mathrm{Co}(\mathrm{II}), \mathrm{Cu}(\mathrm{II}), \mathrm{Ni}(\mathrm{II}), \mathrm{Pd}(\mathrm{II}), \mathrm{Pt}(\mathrm{IV})$ and $\mathrm{Zn}(\mathrm{II})$ have been carried out. Table 2 shows the recovery percent for each metal in a steady state operation. Initial concentrations of each metal and hydrochloric acid were $20 \mathrm{ppm}$ and $2.0 \mathrm{M}$, respectively. Sixty-four \% of $\mathrm{Au}$ (III) was recovered from the feed solution, and the enrichment ratio is as high as 4.1. The recovery of the foamate solution was $16 \%$, which corresponds to other metals recovery. This remarkable difference in behavior of $\mathrm{Au}(\mathrm{III})$ and the other metals is ascribed to their difference in affinity to the surfactant. Metals except for $\mathrm{Au}(\mathrm{III})$ are not adsorbed onto the foam surface but transferred within the interstitial water into the foamate phase. A similar tendency was also observed in the batch foam separation [12], where the percent recoveries of $\mathrm{Au}(\mathrm{III})$ and the other metals were found to be 86 and $22 \%$, respectively.

Table 2. Result for continuous foam separation from multi-metals solution.

\begin{tabular}{cccccccc}
\hline Element & Au & Co & Cu & Ni & Pd & Pt & Zn \\
\hline Percent Recovery (\%) & 64 & 17 & 16 & 16 & 16 & 17 & 17 \\
Enrichment ratio (-) & 4.1 & 1.1 & 1.0 & 1.1 & 1.0 & 1.1 & 1.1 \\
\hline
\end{tabular}

\section{Mass balance for continuous foam separation of $A u(I I I)$}

In foam separation, transfer of a dissolved solute into the foamate phase follows two distinct paths: A) on the surface of foam stabilized by a surfactant, B) the interstitial water between foam. The degree of adsorption of a solute on the foam surface is generally expressed by the surface excess, $\Gamma$, which is determined from the mass balance on the foamate phase $[3,9,12]$ :

$$
\mathrm{L}[\mathrm{M}]_{\mathrm{fm}}=\mathrm{S} \Gamma+\mathrm{L}[\mathrm{M}]_{\mathrm{ret}}
$$

where $\mathrm{S}$ is the surface generation rate and the subscript, ret, denotes the retentate phase. The first term in the right hand side of Equation (4) corresponds to the above mentioned path $\mathrm{A}$, and the second one to the path B. In the present continuous operation, a mass balance for the metal is given by the following relation:

$$
\mathrm{F}[\mathrm{M}]_{\mathrm{ini}}=\mathrm{L}[\mathrm{M}]_{\mathrm{fm}}+\mathrm{G}[\mathrm{M}]_{\mathrm{ret}}
$$


where $\mathrm{G}$ denotes the volumetric flow rate of the effluent solution, i.e. drainage rate. At steady state, the metal concentration in the retentate solution, $[\mathrm{M}]_{\text {ret }}$, is constant. Equation (5) can be rewritten using Equation (4) and the relationship, $\mathrm{F}=\mathrm{L}+\mathrm{G}$, as follows:

$$
\mathrm{F}[\mathrm{M}]_{\mathrm{ini}}=\mathrm{S} \Gamma+(\mathrm{L}+\mathrm{G})[\mathrm{M}]_{\mathrm{ret}}=\mathrm{S} \Gamma+\mathrm{F}[\mathrm{M}]_{\mathrm{ret}}
$$

In our previous study [12], following Freundlich's adsorption isotherm (6) was found to express the results of batch foam separation of $\mathrm{Au}(\mathrm{III})$ using PONPE20 through the plot of the surface excess against the mean metal concentration in the retentate solution.

$$
\Gamma \times 10^{7}=10.3[\mathrm{M}]_{\mathrm{ret}}^{0.39}
$$

On the other hand, the relationship between the volumetric flow rates of the feed $(\mathrm{F})$ and foamate (L) solutions is given in Figure 4. The following equation (7) is obtained from the present data.

$$
\mathrm{L}=-0.383+0.614 \mathrm{~F}-0.171 \mathrm{~F}^{2}+0.014 \mathrm{~F}^{3}
$$

By combining Equations (5)', (6) and (7), the modified forms of Equations (2) and (3) are obtained as a function of the feed flow rate.

$$
\begin{gathered}
\mathrm{R}_{\mathrm{M}}=100\left(\mathrm{~L}[\mathrm{M}]_{\mathrm{ret}}+\Gamma \mathrm{S}\right) /\left(\mathrm{F}[\mathrm{M}]_{\mathrm{ini}}\right) \\
\mathrm{E}=\left(\left(\mathrm{L}[\mathrm{M}]_{\mathrm{ret}}+\Gamma \mathrm{S}\right) / \mathrm{L}\right) /[\mathrm{M}]_{\mathrm{ini}}
\end{gathered}
$$




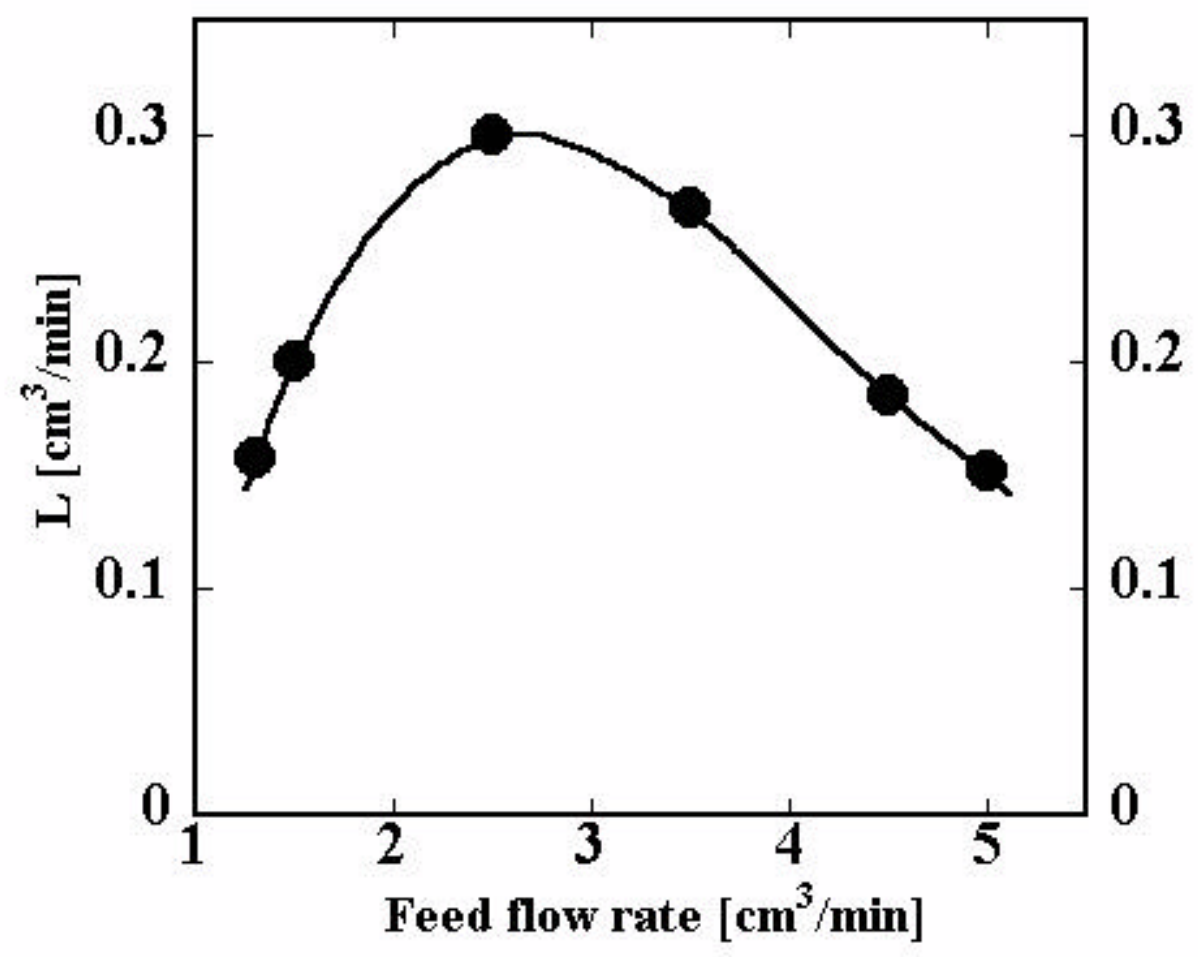

\section{Figure 4. Relationship between volumetric flow rate of feed and foamate solution.}

In Figure 3 calculated results are given by dotted lines, where he surface generation rate (S) is calculated as $6 \mathrm{~W} / \mathrm{d}$, where the air flow rate $(\mathrm{W})$ and an average diameter of foam (d), are presumed to be the same as the value $(0.7 \mathrm{~mm})$ obtained in the batch mode [12]. The calculation agrees well with the experimental data for both the percent recovery and the enrichment ratio of $\mathrm{Au}(\mathrm{III})$. Thus, the process performance in the continuous foam separation can be predicted by the adsorption isotherm and the relationship between the flow rates of feed and foamate solutions.

Since Equation (4) was found to be applicable to the present system, we define the entrainment ratio $(\mathrm{Et})$ as the ratio of the amount of metal transferred on the foam surface to that recovered in the foamate phase, $\Gamma \mathrm{S} /\left(\mathrm{L}[\mathrm{M}]_{\mathrm{ret}}+\Gamma \mathrm{S}\right)$. Figure 5 shows the values of Et as a function of the feed flow rate. Irrespective of the flow rate, the entrainment ratio gives a nearly constant value of 0.90 , indicating the recovered metal is mainly carried on the surface of foam due to the strong interaction between $\mathrm{Au}(\mathrm{III})$ and PONPE20. This finding implies that the metal enrichment is much affected by dilution of the foamate phase by the interstitial water between the rising foams rather than the recovered amount of the metal. Thus, a higher enrichment ratio is attained at a higher feed flow rate, where the recovery of foamate is suppressed, as shown in Figure 3. 


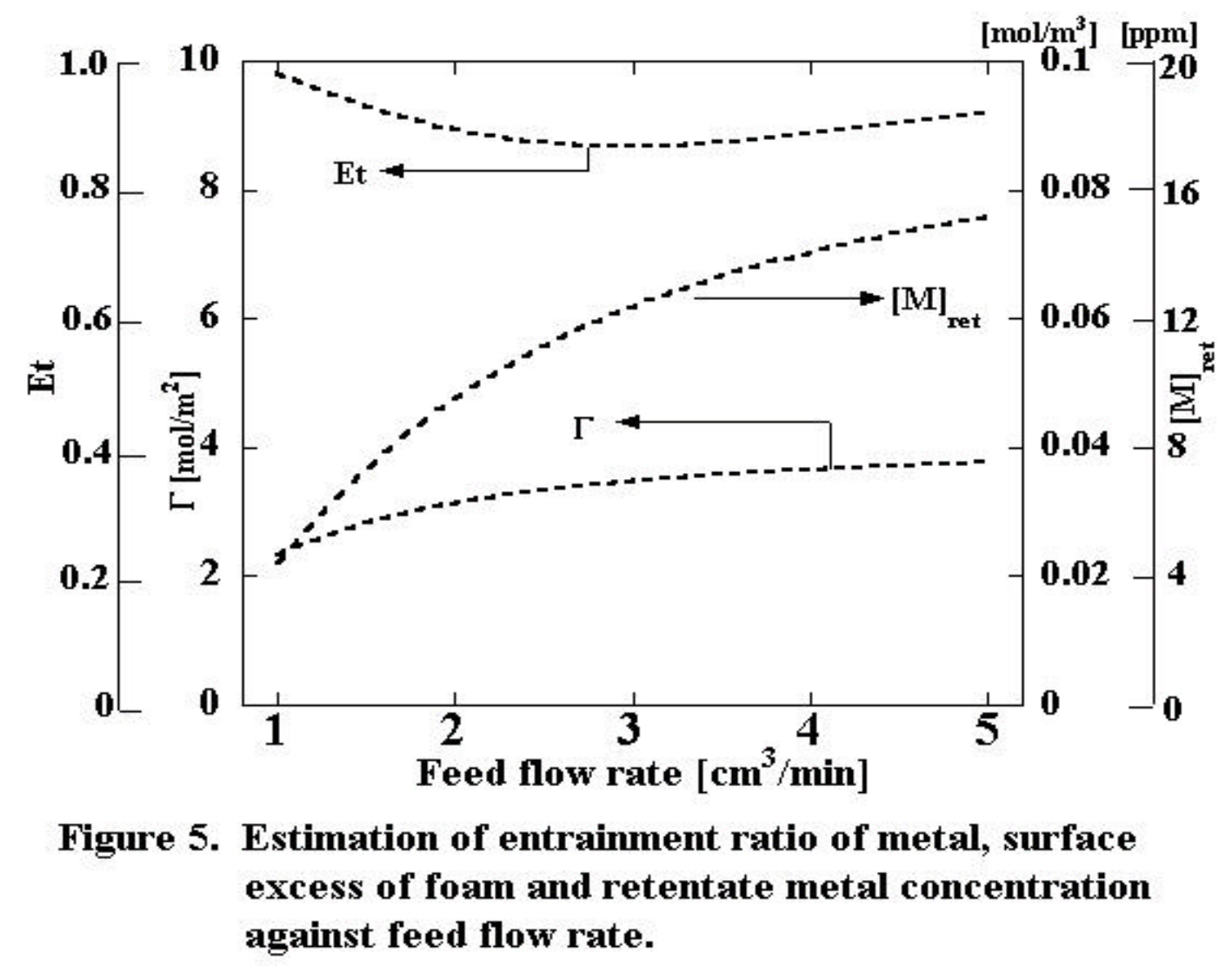

In Figure 5 are also depicted the calculated curves of the surface excess, $\Gamma$, and the metal concentration in the retentate solution. As can be expected, the retentate concentration increased with an increase in the feed flow rate. For instance, $[\mathrm{M}]_{\text {ret }}$ rises as high as $15 \mathrm{ppm}$ at $\mathrm{F}=5.0$ $\mathrm{ml} / \mathrm{min}$, and most of the metal remained intact and was discharged from the column. Compared with the retentate concentration, the surface excess increased more gradually, approaching a constant value of $3.8 \mathrm{~mol} / \mathrm{m}^{2}$. This implies that the interaction between $\mathrm{Au}(\mathrm{III})$ and PONPE20 was so effective that the surface of foam was well occupied by the metal, i.e. saturated, even at a low feed rate. Use of a glass filter having smaller pore size may improve the process efficiency, since it leads to the increased surface generation rate, $\mathrm{S}$. With an intention to improve the enrichment of target solutes one step further in continuous foam separation, a study on the reflux of foamate phase into the retentate solution is now underway.

\section{Conclusions}

Gold(III) recovery from its hydrochloric acid solutions has been investigated. The method employed is foam separation in a continuous operation using a non-ionic surfactant, polyoxyethylene nonyl phenyl ether with 20 ethylene oxide units (PONPE20). Experimental parameters including air flow rate and concentrations of metal, surfactant and $\mathrm{HCl}$ were the same as those determined to be optimum condition in the batch foam separation [12]. After attaining a stable state, Au(III) was continuously recovered from the foamate formed by the feed solution. With an increase in the feed flow rate, the recovery percent of Au(III) decreases proportionally, while the enrichment ratio shows a concave profile with a minimum value at $2.5 \mathrm{ml} / \mathrm{min}$ when 
plotted against the feed flow rate. The enrichment ratio also improved by extending the drainage section of the column. The selective recovery of $\mathrm{Au}(\mathrm{III})$ from a multi-metals solution was successfully attained via continuous foam separation. Using Freundlich's adsorption isotherm obtained in the batch operation [12], the process efficiency was estimated as a function of feed flow rate. A satisfactory agreement was observed between the experimental data and the calculation. Based on the calculation, the entrainment ratio and the surface excess of $\mathrm{Au}$ (III) were estimated, and their effect on the efficiency was discussed.

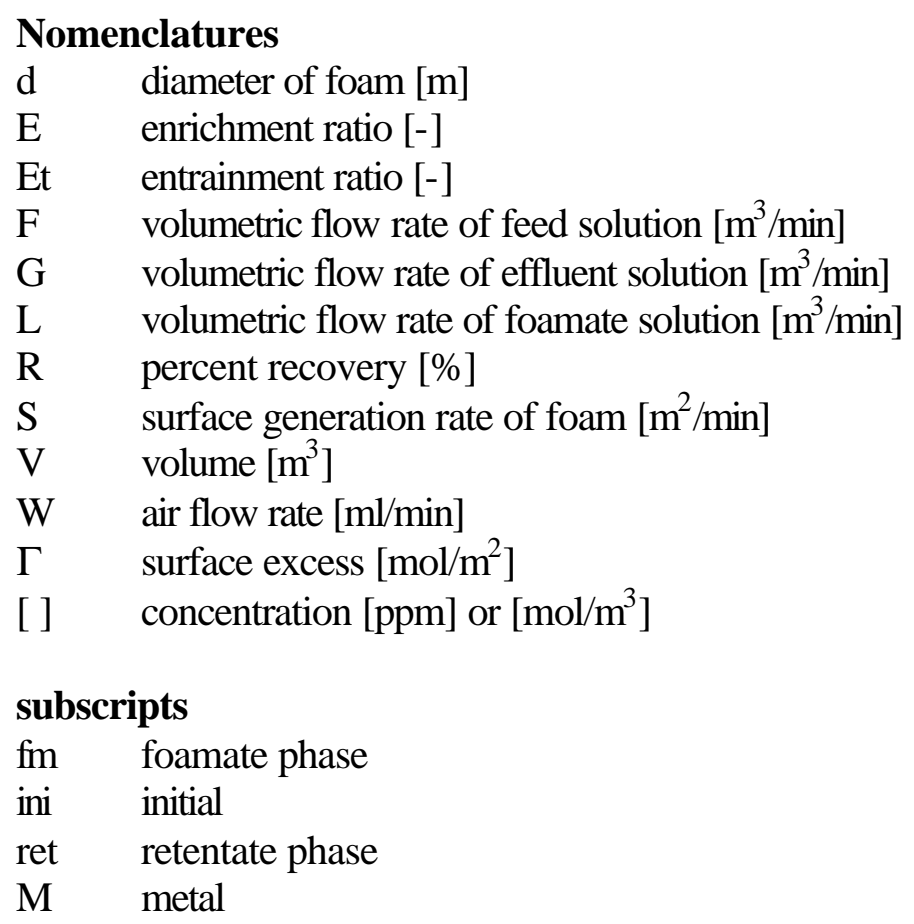

\section{References}

1. Maurice, C. F., et al. 1995, Mineral Processing, In: Flotation Science and Engineering, Part 2, pp.89-259, (Matis, K. A., Eds.), N.Y., Dekker.

2. Thomas, E., et al. 1992, Separations Based on Foams, In: Surfactant-Based Separation Processes, Part IV, pp. 233-320, (Scamehorn, J. F., et al. Eds.), N.Y., Dekker.

3. Maruyama, H., Suzuki, A., Seki, H., 2000, "Adsorption of Water Soluble Proteins onto Bubbles in Continuous Foam Separation", J. Coll. Int. Sci., Vol. 224, pp. 76-83.

4. Bhattacharya, P., Ghosal, S. K., and Sen, K., 1991, "Effect of Physicochemical Parameters on the Separation of Proteins from Human Placental Extract by Using a Continuous Foam Fractionating Column”, Sep. Sci Technol., Vol. 26(10\&11), pp. 1279-1293.

5. Malcolm D. E., Leahy G J., Neville T M. and Stuart K.N. 1991, "Selective Ion Flotation of Gold from Alkaline Cyanide Solutions", AisIMM World Gold '91 Conference Cairns $21^{\text {th }}$ to $26^{\text {th }}$ April, pp. $121-131$.

6. Tharapiwattananon, N., Scamehorn, J.F., Osuwan, S., Harwell, J.H., and Haller, K.J., 1996, "Surfactant Recovery from Water Using Foam Separation", Sep. Sci. Technol., Vol. 31(9), pp. 
$1233-1258$.

7. Koczo, K., and Racz, G., 1991, "Foaming Properties of Surfactant Solution”, Colloids Surf., Vol. 56, pp. 59-82.

8. Uraizee F., and Ganesan, N., 1992, "Effect of Coalescence on the Performance of Continuous Foam Fractionation Column”. Sep. Sci. Technol., Vol. 27(7), pp. 937-953.

9. Konduru, R., 1992, "Adsorption studies of Aqueous Zinc Ions by Foam Fractionation in Simple Mode", J. Chem. Eng. Japan, Vol. 25, No. 5, pp. 555-560.

10. M. Hiraide, 1995, Foam Fractionation and Flotation, In: Encyclopedia of Analytical Science, pp. 1453, (Townshend, A., Eds.), F.L., Academic Press.

11. Akita, S. and Takeuchi, H., 1996, "Cloud Point Extraction of Gold(III) from Hydrochloric Acid Solution, in Value Adding through Solvent Extraction', ISEC '96, Vol.1, pp. 529-534.

12. Kinoshita, T., Akita, S., et al., 2003, "A study on gold(III) recovery via foam separation with nonionic surfactant in batch mode", J. Min. \& Mat. Char. \& Eng., 2003, Vol. 2, No. 2, pp. 7182.

13. Akita, S., Yang, L. and Takeuchi, H., 1996, "Solvent Extraction of Gold(III) from Hydrochloric Acid Media by Nonionic Surfactant", Hydrometallurgy, Vol. 43, pp. 37-46.

14. Akita, S., Rovira, M., Sastre, A. M. and Takeuchi, H., 1998, Cloud Point Extraction of Gold(III) with Nonionic Surfactant - Fundamental Studies and Application to Gold Recovery from Printed Substrates", Sep. Sci. Technol., Vol. 33 (14), pp. 2159-2177.

15. Akita, S., Yang, L. and Takeuchi, H., 1997, "Micellar-enhanced Ultrafiltration of Gold(III) with Nonionic Surfactant”, J. Membrane Science, Vol. 133, pp. 189-194. 